\title{
ATRIBUTOS QUÍMICOS E PERFIL DE ENRAIZAMENTO DE MILHO INFLUENCIADOS PELA CALAGEM EM SEMEADURA DIRETA ${ }^{(1)}$
}

\author{
Gabriel Henrique Melo Nascimento Leite ${ }^{(2)}$, Flávio Luiz Foletto Eltz ${ }^{(3)}$, \\ Telmo Jorge Carneiro Amado ${ }^{(4)} \&$ Neroli Pedro Cogo ${ }^{(5)}$
}

\begin{abstract}
RESUMO
No Rio Grande do Sul, a área sob semeadura direta já alcança 60 \% da área total cultivada para produção de grãos de sequeiro. Todavia, ainda persistem dúvidas com relação não só a eficiência de práticas culturais como a adubação e a calagem, mas também de seus efeitos sobre o crescimento de raízes e a produtividade das culturas. $O$ objetivo deste trabalho foi avaliar o efeito de doses e modos de aplicação de calcário sobre o perfil de enraizamento do milho. $O$ experimento foi realizado no ano agrícola 1999/2000, na área experimental do Departamento de Solos da Universidade Federal de Santa Maria, sendo delineado em blocos ao acaso com parcelas subdivididas e quatro repetições. O solo da área estudada foi um Argissolo Vermelho distrófico arênico. Os tratamentos principais foram: sem calcário (SC), $100 \%$ da dose recomendada incorporada (100I), $25 \%$ $(25 \mathrm{~S}), 50 \%(50 \mathrm{~S})$ e $100 \%(100 \mathrm{~S})$ da dose recomendada $\left(6,8 \mathrm{tha}^{-1}\right)$ aplicada em superfície. A incorporação foi feita por meio de aração e duas gradagens em fevereiro de 1996. As principais avaliações no solo foram $\mathrm{pH}$ e teores de $\mathrm{Al}^{3+}, \mathrm{Ca}^{2+}$ e $\mathrm{Mg}^{2+}$, determinadas em amostras coletadas nas profundidades de $0,0-0,5,0,5-$ $0,10,0,10-0,20,0,20-0,30$ e 0,30-0,45 m, que se constituíram nas subparcelas. Pelo método da prancha com pregos, com dimensões $0,20 \times 0,30,0,30 \times 0,45$ e $0,45 \times 0,70 \mathrm{~m}$, retiraram-se monolitos no perfil do solo paralelos à linha de semeadura aos 20, 54 e 80 dias da emergência (DAE), os quais foram cuidadosamente lavados, e as raízes contadas para compor o perfil de enraizamento do milho em cada tratamento. O aumento das doses de calcário aplicado em superfície $(25 \mathrm{~S}, 50 \mathrm{~S}$ e 100S) proporcionou aumento na profundidade em que foram observadas elevações
\end{abstract}

\footnotetext{
(1) Parte da Tese de Mestrado do primeiro autor, apresentada ao Programa de Pós-Graduação em Agronomia, Universidade Federal de Santa Maria - UFSM. Recebido para publicação em maio de 2004 e aprovado em maio de 2006.

(2) Engenheiro MSc.

(3) Professor Titular do Departamento de Solos da Universidade Federal de Santa Maria - UFSM. CEP 97105-900 Santa Maria (RS) Bolsista do CNPQ. E-mail: feltz@ccr.ufsm.br

(4) Professor Adjunto do Departamento de Solos, UFSM. Bolsista do CNPQ. E-mail: tamado@smail.ufsm.br

(5) Professor Adjunto do Departamento de Solos da Universidade Federal do Rio Grande do Sul. Bolsista do CNPq. E-mail: neroli@ufrgs.br
} 
dos valores de $\mathrm{pH}$ e teores de $\mathrm{Ca}^{2+}$ e $\mathrm{Mg}^{2+}$ e redução do $\mathrm{Al}^{3+}$. No tratamento 100I,

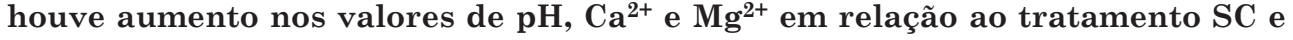
redução dos teores de $\mathrm{Al}^{3+}$ até à camada de $0,20-0,30 \mathrm{~m}$. Mesmo sob condições químicas adversas, em todos os tratamentos, o milho apresentou crescimento de raízes até $0,45 \mathrm{~m}$ de profundidade. $O$ tratamento $100 \mathrm{I}$ apresentou maior crescimento de raízes até $0,15-0,20 \mathrm{~m}$ de profundidade do que os tratamentos com doses menores de calcário em superfície (50S e 25S), onde as raízes se concentraram na camada até $0,075 \mathrm{~m}$. A incorporação do calcário proporcionou maior uniformidade na neutralização da acidez do solo em profundidade, o que se refletiu em maior quantidade de raízes até $0,45 \mathrm{~m}$.

Termos de indexação: correção da acidez, manejo do solo, raiz, Zea mays, atributos químicos.

\section{SUMMARY: CHEMICAL ATTRIBUTES AND CORN ROOT SYSTEM DEVELOPMENT AS AFFECTED BY LIMING IN NO-TILL}

In Rio Grande do Sul state, the area cultivated with under no-till system now amounts to $60 \%$ of the total rain-fed cultivated area. However, there are still doubts as to crop practices in this soil conservation system, such as liming and fertilization as well as regarding root growth and crop productivity. The objective of this study was to evaluate the effects of lime doses and application forms on corn root development. The experiment was carried out in 1999/2000, in the experimental area of the Soil Science Department of the Federal University of Santa Maria, state of Rio Grande do Sul, Brazil, in a random block design in split plots, with four replications. The soil under study was a typical Hapludalf with $2 \%$ slope. Main treatments were: no lime (SC), incorporation of $100 \%$ of the recommended dose (100I), and $25 \%(25 S)$,

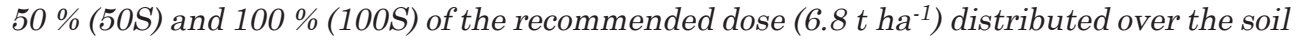
surface. Lime was incorporated with conventional tillage in February 1996. Using the "nail board" method, with dimensions of 0,20 x 0,30 m, 0,30 x 0,45 $\mathrm{m}$ and 0,45 $\mathrm{x} 0,70 \mathrm{~m}$, monoliths were taken from the soil profile, parallel to the corn sowing furrow, at 20, 54 and 80 days after corn emergence (DAE). The monoliths were carefully washed and the roots counted to establish a corn rooting profile in each treatment. Increasing lime doses applied on the soil surface (25S, 50S and 100S) increased the depth at which elevations in $\mathrm{pH}, \mathrm{Ca}^{2+}$ and $\mathrm{Mg}^{2+}$ concentration and $\mathrm{Al}^{3+}$ reduction were observed. In the treatment $100 \mathrm{I}$ there was an increase in $\mathrm{pH}, \mathrm{Ca}^{2+}$ and $\mathrm{Mg}^{2+}$ and a decrease in the $\mathrm{Al}^{3+}$ concentration down to 0,20-0,30 m compared to the SC treatment. Even under adverse acid conditions, the root profile showed there was root development down to $0,45 \mathrm{~m}$ in all treatments. Treatment $100 \mathrm{I}$ showed greater root development down to a depth of 0,15-0,20 m than treatments with lower surface lime doses (50s and 25S), where roots were more concentrated down to 0,075 m. Lime incorporation (100I) led to a more uniform neutralization of acidity at deeper soil layers, which reflected in a improved root system down to 0,45 $\mathrm{m}$.

Index terms: liming, soil management, roots, Zea mays, chemical attributes.

\section{INTRODUÇÃO}

As estimativas evidenciam que, atualmente, aproximadamente 16 milhões de hectares do território brasileiro são cultivados, anualmente, no sistema semeadura direta, sendo os três Estados da Região Sul do Brasil responsáveis por mais de $60 \%$ dessa área (Cervi, 2001). A área de lavoura sob semeadura direta cresceu linearmente no Rio Grande do Sul durante a década de 90 , chegando a atingir $60 \%$ da área cultivada (Amado \& Reinert, 1998).

A Região da Depressão Central do Rio Grande do Sul apresenta solos ácidos e com presença subsuperficial de Al trocável. Tradicionalmente, a calagem tem sido utilizada para corrigir a acidez e propiciar melhores condições de crescimento e desenvolvimento das plantas cultivadas, principalmente quando o preparo convencional do solo era o sistema de manejo mais utilizado pelos agricultores.

A calagem influencia o crescimento das culturas, já que interfere diretamente na toxidez de $\mathrm{Al}$, que restringe o crescimento radicular. Dessa maneira, propicia condições favoráveis ao crescimento e desenvolvimento das plantas. Entretanto, experimentos sob semeadura direta em lavouras já cultivadas e em campo nativo têm mostrado resposta diferenciada das cultu- 
ras à calagem, em relação à verificada no preparo convencional. Assim, estudos que visem estabelecer manejos mais eficientes e menos dispendiosos de correção da acidez dos solos cultivados sob o sistema semeadura direta constituem prioridades de pesquisa.

O calcário aplicado na superfície do solo na semeadura direta pode mover-se para as camadas mais profundas por meio de uma rede de poros contínuos formada por raízes senescentes e pela micro e macrofauna do solo (Eltz et al., 1989), podendo estes poros atingir até $0,5 \mathrm{~m}$ de profundidade (Lal \& Van Doren Jr., 1998). As plantas podem ter mecanismos de tolerância à absorção de $\mathrm{Al}^{3+}$ que dependem da planta (Faquim \& Vale, 1991). Aplicações superficiais de calcário podem atingir até $0,20 \mathrm{~m}$ em 10 anos (Hargrove et al., 1982), sendo suficientes para não limitar o crescimento e desenvolvimento das plantas (Mielniczuk et al., 1995)

O conhecimento das variáveis que regem o crescimento do sistema radicular das plantas é de grande importância agrícola, já que esse permite o crescimento e o estabelecimento das culturas, determinando, conseqüentemente, a produtividade dos agroecossistemas.

A distribuição e a atividade das raízes determinam a quantidade de água e nutrientes absorvidos (Daros et al., 1999), e, no entanto, ainda há carência de estudos a este respeito.

O presente trabalho teve como objetivo o estudo de modos de aplicação e doses de calcário em sistema semeadura direta sobre o crescimento do sistema radicular da cultura do milho e sobre alguns atributos químicos do solo.

\section{MATERIAL E MÉTODOS}

O experimento foi instalado na área experimental do Departamento de Solos da Universidade Federal de Santa Maria - UFSM, localizada no Município de Santa Maria, na região fisiográfica da Depressão Central do Estado do Rio Grande do Sul. O clima da região é classificado como $\mathrm{Cfa}$, subtropical úmido, segundo Koeppen, com precipitações médias anuais de 1.400 a $1.700 \mathrm{~mm}$ e temperaturas médias entre 17,9 e $19,2{ }^{\circ} \mathrm{C}$. O solo, segundo o Sistema Brasileiro de Classificação de Solos (Embrapa, 1999), é um Argissolo Vermelho distrófico arênico e pertence à unidade de mapeamento São Pedro (Brasil, 1973), com declive de $2 \%$. O experimento foi iniciado sobre pastagem nativa, em 1996, em solo com $\mathrm{pH}$ (água) de 4,4 , teor de matéria orgânica de $24 \mathrm{~g} \mathrm{dm}^{-3}, 8 \mathrm{~g} \mathrm{dm}^{-3}$ de $\mathrm{P}, 134 \mathrm{~g} \mathrm{dm}^{-3}$ de $\mathrm{K}, 2 \mathrm{cmol}_{\mathrm{c}} \mathrm{dm}^{-3} \mathrm{de} \mathrm{Al}^{3+}$,

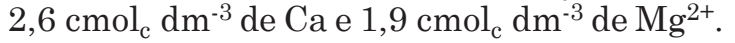

O delineamento experimental foi em blocos ao acaso, com parcelas subdivididas e quatro repetições. A dose de calcário dolomítico recomendada para $1 \mathrm{SMP}$ correspondeu a 6,8 $\mathrm{t} \mathrm{ha}^{-1}$ (PRNT $100 \%$ ) Os tratamentos principais consistiram em: testemunha (sem aplicação de calcário, SC); dose recomendada de calcário, incorporada ao solo numa profundidade de 0,20 m (100I); dose recomendada de calcário distribuída na superfície do solo (100S); metade da dose recomendada distribuída na superfície do solo (50S) e um quarto da dose recomendada distribuída na superfície do solo (25S).

O experimento foi implantado em fevereiro de 1996, quando o calcário foi aplicado em superfície, por meio de distribuição manual, ou incorporado, por meio de uma aração a $0,20 \mathrm{~m}$ e duas gradagens. As parcelas principais tiveram dimensões de $5 \times 10 \mathrm{~m}$. Analisouse a fertilidade do solo antes, durante e após o experimento, utilizando-se de amostras de solo retiradas com trado calador nas profundidades de $0,0-0,05$, 0,05-0,10, 0,10-0,20, 0,20-0,30 e 0,30-0,45 m. Aárea encontrava-se sob sistema semeadura direta há quatro anos com a seguinte seqüência de culturas: aveia preta/soja, aveia preta/milho, aveia preta/soja e ervilha forrageira. Em 25/12/1999, semeou-se milho (Zea mays L.), com re-semeadura realizada em 12/ 01/2000 em decorrência do déficit hídrico, com o cultivar Agroceres AG 3010, no espaçamento de $0,90 \mathrm{~m}$ entre linhas e densidade de seis plantas por metro linear. A adubação de $150 \mathrm{~kg} \mathrm{ha}^{-1}$ da fórmula 05-20-30 foi aplicada na semeadura, acrescida de uréia em cobertura 47 dias após a emergência, na dose de $120 \mathrm{~kg} \mathrm{ha}^{-1} \mathrm{de} \mathrm{N}$, segundo recomendações de Comissão (1994).

O crescimento do sistema radicular do milho foi avaliado aos 20, 54 e 80 dias, por meio do método do monolito (prancha com pregos) e do perfil de enraizamento. Para a utilização do método da prancha com pregos (Bohm, 1979), adaptado por Pedó (1986), foram construídos três monolitos, com pregos espaçados de 0,05 em 0,05 m. O procedimento de campo consistiu na abertura de uma trincheira para permitir acesso ao sistema radicular. Em paredes verticais de trincheiras de solo, de 1,0 m de largura e $0,80 \mathrm{~m}$ de profundidade, foram moldados perfis, paralelamente à linha da cultura e a uma distância de aproximadamente $0,4 \mathrm{~m}$ desta. As pranchas foram pressionadas de modo que os pregos penetrassem no solo, possibilitando retirar um bloco de solo que incluiu as raízes. Logo após a retirada da prancha, esta foi imersa em um lavatório construído no campo com dimensões de $1,5 \times 6,0$ x 0,2 m, onde permaneceu por 15 min, para a obtenção do perfil radicular com danos minimizados.

O método do perfil de enraizamento é feito com a exposição do sistema radicular, no monolito já lavado, sobre uma malha de arame com quadrículas de $0,25 \times 0,25 \mathrm{~m}$, sendo, posteriormente, contadas todas as raízes em cada malha.

Os valores para a quantidade de raízes foram classificados e notificados como sendo zero (0) para a ausência de raízes; (1) para uma raiz, (2) para duas e 
(3) para três ou mais raízes. Com estes dados, foram confeccionados mapas de enraizamento, para relacionar a distribuição das raízes com a profundidade no perfil do solo.

Foram determinados, nas amostras de solo, o $\mathrm{pH}$ em água e os teores de $\mathrm{Ca}, \mathrm{Mg}$ e $\mathrm{Al}$ trocáveis, segundo Tedesco et al. (1995). Utilizou-se o teste de Duncan a $5 \%$ para a comparação de médias.

\section{RESULTADOS E DISCUSSÃO}

\section{Atributos químicos de solo}

O tratamento SC apresentou menores valores de $\mathrm{pH}$ no perfil do solo em relação ao tratamento 100I, até $0,20-0,30 \mathrm{~m}$, e ao tratamento $100 \mathrm{~S}$, até $0,05-$ $0,10 \mathrm{~m}$, mostrando valores similares aos do tratamento $25 \mathrm{~S}$ e apenas sendo inferior ao do tratamento com 50S, na camada de 0,0-0,05 m (Figura 1). O menor valor de $\mathrm{pH}$ do $\mathrm{SC}$ em relação aos demais tratamentos deveu-se não só à elevação do $\mathrm{pH}$ nos demais tratamentos proporcionada pela aplicação de calcário, mas também a processos isolados ou combinados de reacidificação natural do solo oriundo da absorção de cátions básicos pelas culturas, pela mineralização da matéria orgânica do solo e resíduos vegetais na camada superficial e, ou, pelo empobrecimento de bases por lixiviação (Salet, 1994; Cassol \& Anghinoni, 1995). No tratamento 100I, o maior contato calcário-solo favoreceu maior reação do corretivo e, por isto, este tratamento apresentou valores de $\mathrm{pH}$ mais elevados até $0,20-0,30 \mathrm{~m}$, em relação ao tratamento $\mathrm{SC}$ (Figura 1). Isto proporcionou uma maior uniformidade de correção do solo em profundidade.

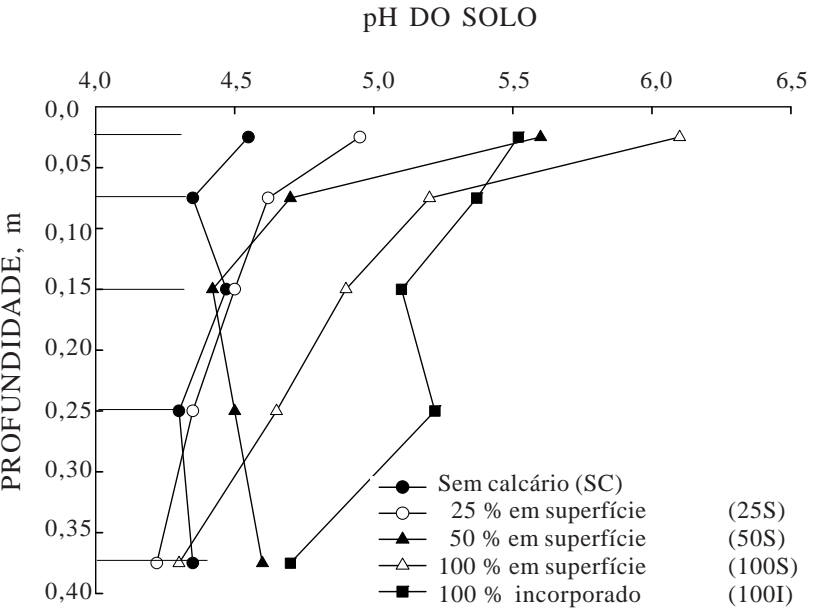

Figura 1. Valores de pH em água em cinco camadas do Argissolo Vermelho distrófico arênico cultivado com milho sob semeadura direta. Barras horizontais representam o DMS.
Os tratamentos 50S e 100S apresentaram um aumento nos valores de $\mathrm{pH}$ nas camadas superficiais do solo em relação à testemunha $\mathrm{SC}$, tendo sido tal efeito proporcionado pela quantidade de calcário depositada em superfície, como observado por Caires \& Fonseca (2000), que facilitou sua movimentação pela rede de poros contínuos formada pelas raízes das culturas anteriores ou pela meso e macrofauna do solo, conforme relatado por Vidor (1984). O tratamento $25 \mathrm{~S}$ apresentou no perfil do solo valores de $\mathrm{pH}$ similares aos do tratamento SC (Figura 1). Este resultado deveu-se, provavelmente, à pequena quantidade de calcário depositada em superfície e, ou, à perda do efeito residual do corretivo, visto que estas determinações foram feitas quatro anos após a aplicação do calcário.

Os tratamentos $25 \mathrm{~S}$ e $100 \mathrm{~S}$ apresentaram maiores valores de $\mathrm{pH}$ na camada de $0,0-0,05 \mathrm{~m}$ e menores na de $0,30-0,45 \mathrm{~m}$, indicando pouca mobilidade no perfil durante o período de quatro anos. O tratamento 50S apresentou maior $\mathrm{pH}$ na camada de $0,0-0,05 \mathrm{~m}$ do que nas camadas de $0,10-0,20 \mathrm{e}$ 0,20-0,30 m (Figura 1), fato também atribuído à deposição em superfície e à pequena mobilidade do calcário. O tratamento $\mathrm{SC}$ não apresentou diferenças nos valores de $\mathrm{pH}$ entre as camadas estudadas. No tratamento 100I, a incorporação do calcário proporcionou uma mistura deste com o solo que resultou na similaridade de valores observada nas camadas estudadas. A incorporação proporcionou um bom contato solo-calcário, havendo reação na profundidade de informação e, provavelmente, não restando material para outra frente de correção de acidez em profundidade.

Em relação aos teores de $\mathrm{Al}^{3+}$ no solo, na camada de $0,0-0,05 \mathrm{~m}$, o tratamento $\mathrm{SC}$ apresentou o maior valor que os demais (Figura 2). Este resultado é atribuído à correção propiciada pelo calcário aplicado em superfície ou incorporado. Na camada de 0,20$0,30 \mathrm{~m}$, os tratamentos SC, 25S e 100S apresentaram maiores teores de $\mathrm{Al}^{3+}$ no solo, atribuindo-se este fato à pouca mobilidade e quantidade do corretivo para alcançar esta camada de solo. Neste caso, a falta de mobilidade é devida à reação do calcário com o solo no tratamento incorporado, não restando mais para reagir em profundidade e, no tratamento em superfície, a pequena quantidade também reage e não resta mais para descer no perfil do solo.

Houve tendência de aumento no teor de $\mathrm{Al}^{3+}$ com o aumento da profundidade no perfil do solo, em todos os tratamentos (Figura 2).

Em relação ao $\mathrm{Ca}^{2+}$, o tratamento $100 \mathrm{~S}$ apresentou maior teor de $\mathrm{Ca}^{2+}$ na camada de $0-0,5 \mathrm{~m}$, graças à grande quantidade de calcário aplicada na superfície do solo (Figura 3). As diferenças entre tratamentos foram menores na profundidade de 0,05-0,10 m, com os tratamentos 100S e 100I, mostrando maiores teores de $\mathrm{Ca}^{2+}$ que os tratamentos SC, 25S e 50S (Figura 3). Resultados semelhantes foram obtidos por Pöttker et al. (1998). Na camada de 0,10-0,20 m de profundidade, 
os tratamentos 100S e 100I mostraram teores de $\mathrm{Ca}^{2+}$ maiores do que os dos demais tratamentos. O maior teor nesta profundidade pode ser atribuído à incorporação do calcário (100I). Franchini et al. (1999) encontraram resultados semelhantes quando da aplicação de calcário em superfície, o que foi atribuído à formação de par iônico ou ligantes por meio de compostos orgânicos liberados pela decomposição de resíduos depositados em superfície. A incorporação do calcário no tratamento 100I proporcionou aumento no teor de $\mathrm{Ca}^{2+}$ na profundidade de $0,20-0,30 \mathrm{~m}$, embora a incorporação tenha sido apenas até $0,20 \mathrm{~m}$ de profundidade.

$\mathrm{Al}^{3+} \mathrm{NO}$ SOLO, $\mathrm{cmol}_{\mathrm{C}} \mathrm{dm}^{-3}$

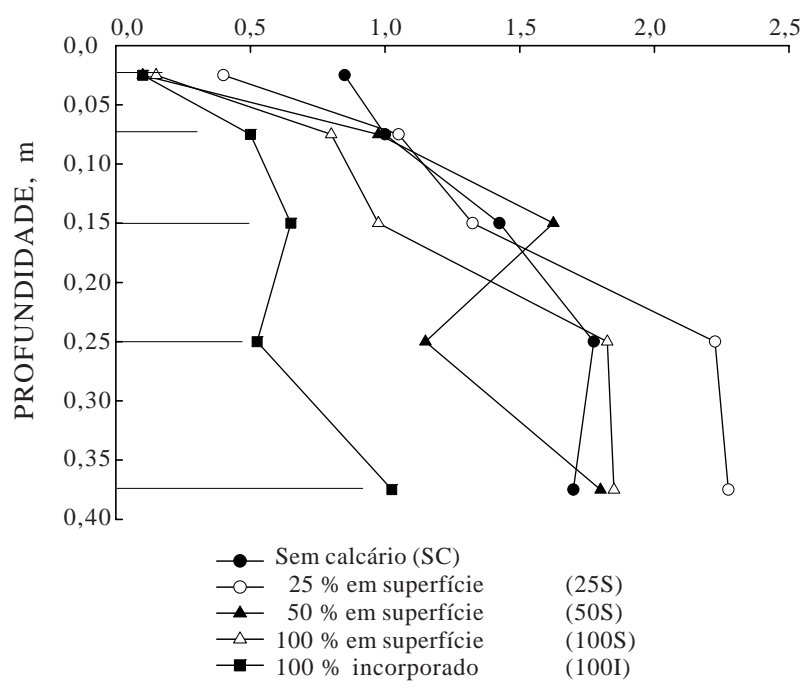

Figura 2. Teores de $\mathrm{Al}^{3+}$ em cinco camadas do Argissolo Vermelho distrófico arênico cultivado com milho sob semeadura direta. Barras horizontais representam o DMS.

\section{$\mathrm{Ca}^{2+} \mathrm{NO}$ SOLO, $\mathrm{cmol}_{\mathrm{c}} \mathrm{dm}^{-3}$}

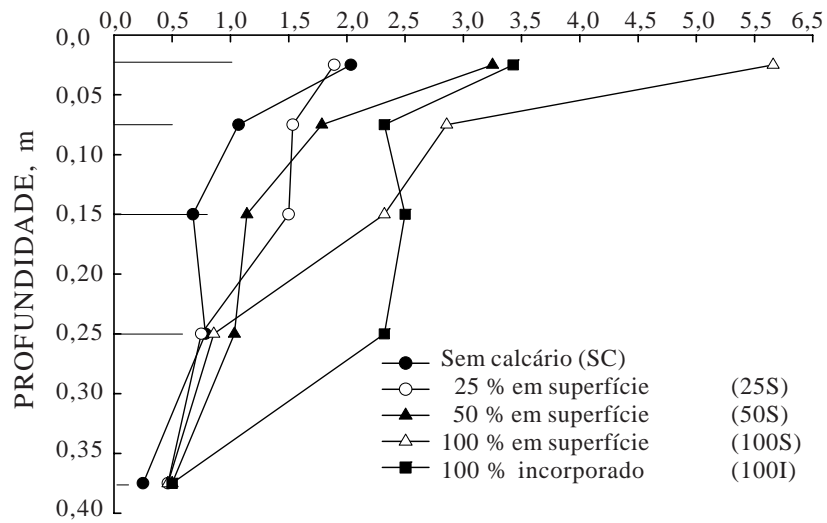

Figura 3. Teores de $\mathrm{Ca}^{2+}$ em cinco camadas do Argissolo Vermelho distrófico arênico cultivado com milho sob semeadura direta. Barras horizontais representam o DMS.
Houve tendência de diminuição no teor de $\mathrm{Ca}^{2+}$ com o aumento da profundidade no perfil do solo (Figura 3). Em relação aos teores de $\mathrm{Mg}^{2+}$, o tratamento $100 \mathrm{~S}$ apresentou maior teor na camada de $0,0-0,05 \mathrm{~m}$, em razão da maior quantidade de calcário aplicada na superfície do solo, seguido do tratamento 50S. Estes resultados evidenciam o efeito da aplicação de doses maiores de calcário em superfície. Os tratamentos SC e 25S tiveram os menores teores nesta camada, o que reflete a pequena quantidade ou a omissão de aplicação (Figura 4).

$\mathrm{Na}$ camada de 0,05-0,10 m, o tratamento SC mostrou o menor teor de $\mathrm{Mg}^{2+}$ em relação aos demais tratamentos (Figura 4), enquanto os tratamentos $25 \mathrm{~S}$ e 50S compuseram um grupo intermediário. Nessa camada, os tratamentos 100I e 100S apresentaram maior teor de $\mathrm{Mg}^{2+}$. Na camada de $0,10-0,20 \mathrm{~m}$, os tratamentos 100I e 100S mostraram maiores teores de $\mathrm{Mg}^{2+}$ do que SC, 25S e 50S, indicando o efeito da descida de $\mathrm{Mg}^{2+}$ com a dose de $100 \mathrm{~S}$. Na camada de 0,20-0,30 m, o tratamento 100I apresentou maior teor com relação aos demais tratamentos, com a incorporação do calcário. Na camada de $0,30-0,45 \mathrm{~m}$, todos os tratamentos apresentaram teores similares de $\mathrm{Mg}^{2+}$, mostrando que as doses aplicadas não tiveram efeito nesta profundidade.

De acordo com os resultados, o alcance das modificações nos valores de $\mathrm{pH}$ e nos teores de $\mathrm{Al}^{3+}$, $\mathrm{Ca}^{2+} \mathrm{e} \mathrm{Mg}^{2+}$ foi diretamente proporcional à quantidade aplicada em superfície, ou seja, o tratamento $25 \mathrm{~S}$ apresentou modificações até à profundidade de $0,05 \mathrm{~m}$, o tratamento $50 \mathrm{~S}$, até à profundidade de $0,10 \mathrm{~m}$, e o tratamento $100 \mathrm{~S}$, até à profundidade de $0,20 \mathrm{~m}$. Isto indica que o efeito residual do uso de $25 \%$ da dose recomendada não alcança quatro anos e, portanto, requer reaplicações mais freqüentes. O rendimento de grãos da cultura do milho foi de 5.510, 5.740, 5.633, 5.455 e $5.788 \mathrm{~kg} \mathrm{ha}^{-1}$, respectivamente, para os tratamentos SC, 100I, 100S, 50S e 25S, não obtendo

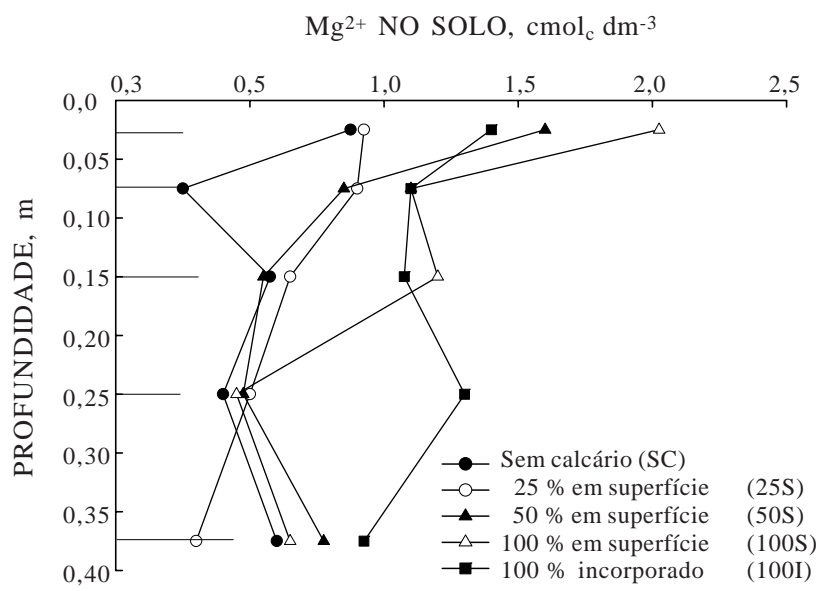

Figura 4. Teores de $\mathrm{Mg}^{2+}$ em cinco camadas do Argissolo Vermelho distrófico arênico cultivado com milho sob semeadura direta. Barras horizontais representam o DMS. 
diferença estatística significativa, o que demonstra que, aparentemente, estas condições de solo não chegaram a afetar o rendimento de grãos.

\section{Perfil radicular da cultura do milho}

Aos 20 dias da emergência, os perfis de enraizamento dos tratamentos 100S e 100I apresentaram-se similares (Figura 5). A incorporação do calcário não causou diferenças na distribuição de raízes no perfil do solo. Nesta avaliação, os tratamentos SC e 25S também apresentaram perfis de enraizamento semelhantes (Figura 5). Este resultado pode estar relacionado com a menor quantidade depositada em superfície, com baixo poder residual após quatro anos da aplicação do calcário. O tratamento 50S apresentou maior quantidade de raízes que os tratamentos $\mathrm{SC} \mathrm{e}$
25S (Figura 5), provavelmente em razão da maior dose de calcário aplicada.

Aos 54 dias da emergência, manteve-se a mesma tendência verificada já aos 30 dias, quando o tratamento 100I mostrou maior crescimento de raízes que o tratamento com a mesma dose aplicada na superfície do solo. O tratamento SC mostrou menor crescimento de raízes que os tratamentos 25S e 50S, os quais foram similares (Figura 6).

Aos 80 dias da emergência, o tratamento 100I apresentou maior quantidade de raízes no perfil (Figura 7), proporcionada pela incorporação do calcário. Nos tratamentos em que o calcário foi aplicado em superfície, observou-se maior concentração de raízes nas camadas superficiais decorrente do maior $\mathrm{pH}$, menor teor de $\mathrm{Al}^{3+}$ e maiores teores de $\mathrm{Ca}^{2+} \mathrm{e}$

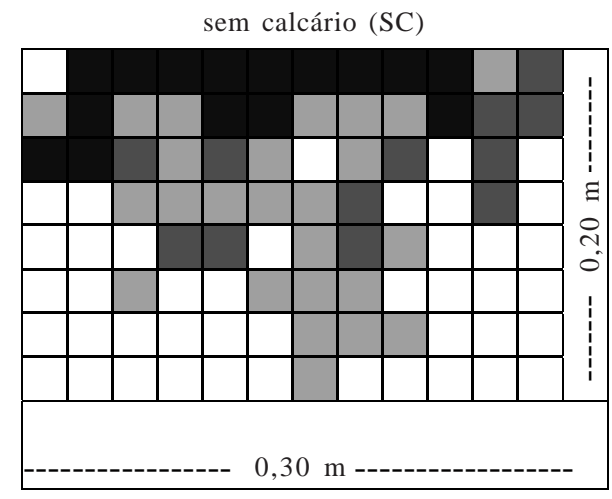

$25 \%$ da dose em superfície (25S)

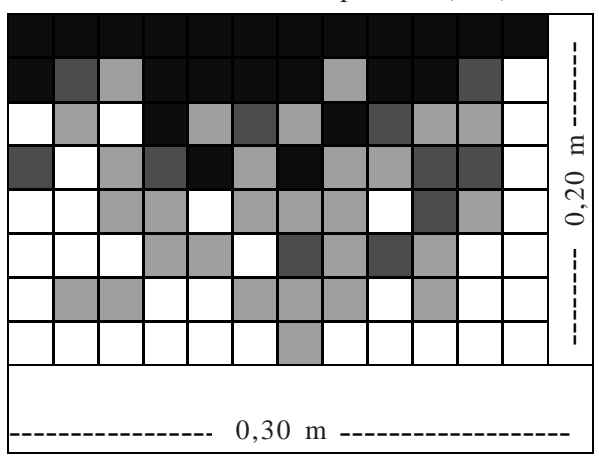

$50 \%$ da dose em superfície (50S)

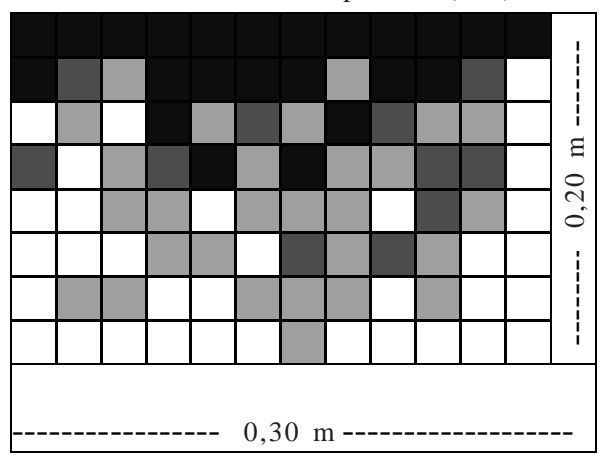

$100 \%$ da dose em superfície (100S)

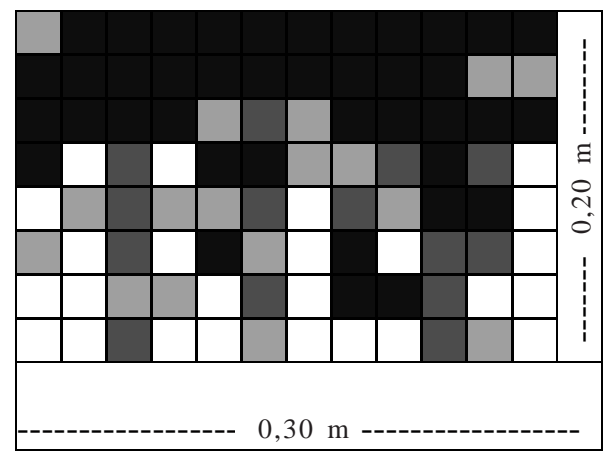

$100 \%$ da dose incorporada (100I)
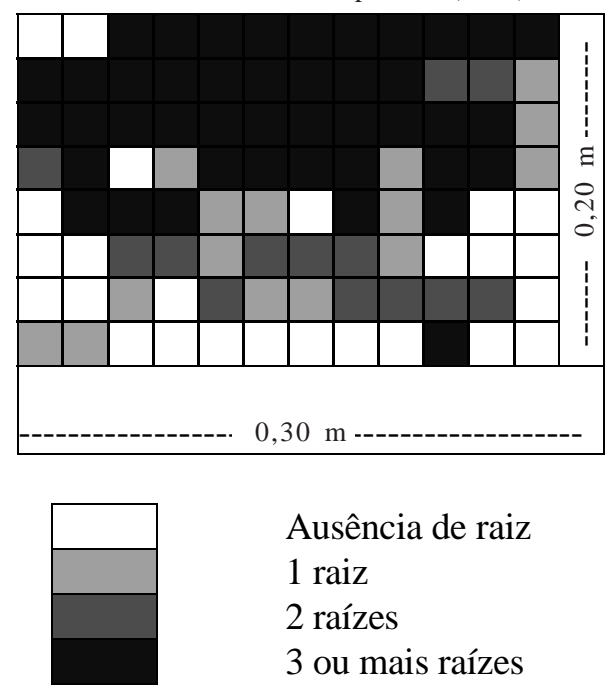

Ausência de raiz

1 raiz

2 raízes

3 ou mais raízes

Figura 5. Perfil de enraizamento da cultura do milho aos 20 dias da emergência no Argissolo Vermelho distrófico arênico sob semeadura direta. 


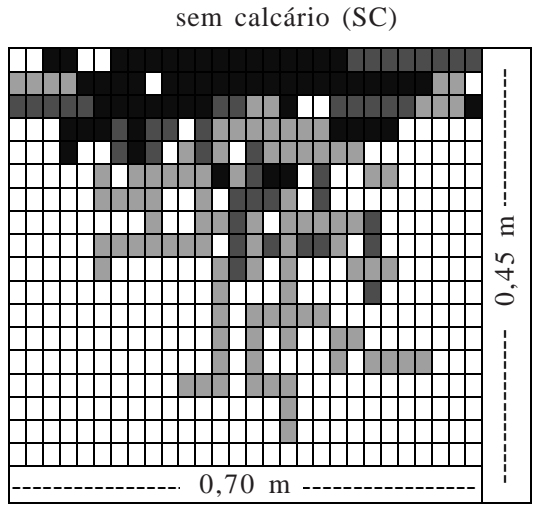

$25 \%$ da dose em superfície (25S)

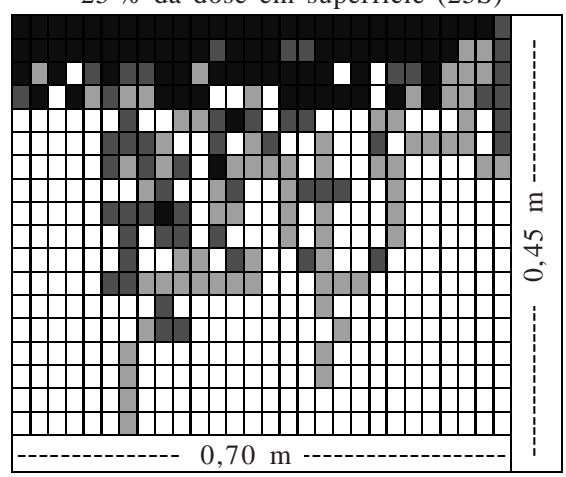

$50 \%$ da dose em superfície (50S)

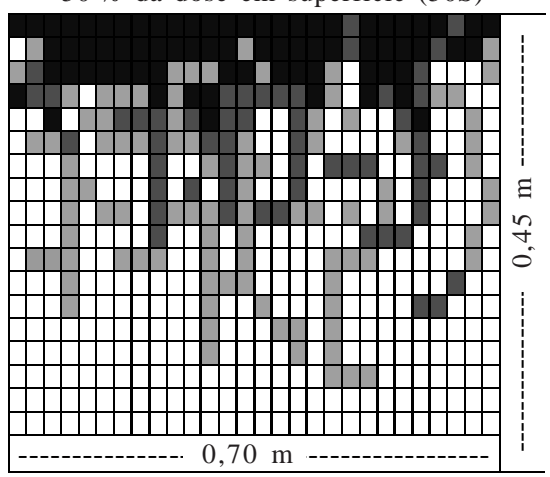

$100 \%$ da dose em superfície (100S)

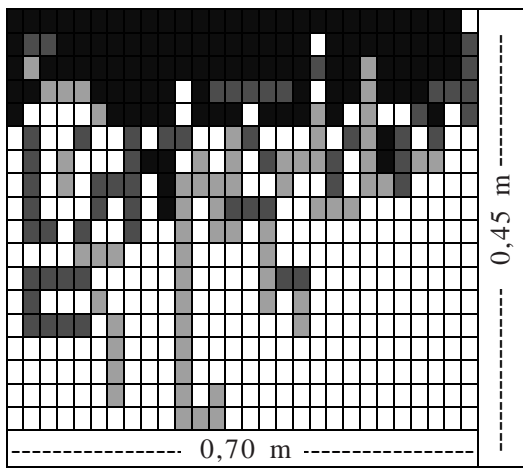

$100 \%$ da dose incorporada (100I)
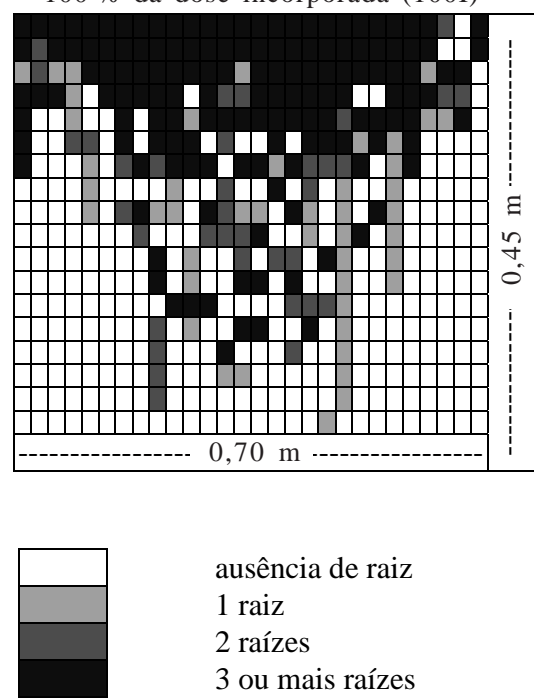

ausência de raiz

1 raiz

2 raízes

3 ou mais raízes

Figura 6. Perfil de enraizamento da cultura do milho aos 54 dias da emergência no Argissolo Vermelho distrófico arênico sob semeadura direta.

$\mathrm{Mg}^{2+}$ no solo. O tratamento SC apresentou menor quantidade de raízes no perfil estudado.

Em todos os tratamentos, mesmo no que não recebeu calcário, observou-se a presença de raízes nas maiores profundidades de avaliação (Figuras 5, 6, e 7); as quais podem estar penetrando em canais formados por raízes senescentes de culturas anteriores ou poros biológicos (Eltz et al., 1989).

O tratamento $100 \mathrm{~S}$ apresentou maior quantidade de raízes até $0,15-0,20 \mathrm{~m}$ de profundidade (Figuras 5 , 6, e 7), em decorrência da diminuição nos teores de $\mathrm{Al}^{3+}$ até à camada de 0,10-0,20 $\mathrm{m}$ (Figura 2). Na camada de 0,0-0,05 m, apresentou menor teor de $\mathrm{Al}^{3+}$ que a maior parte das profundidades do perfil. Para
Santos (1997), isto pode ser decorrente da migração das partículas finas de calcário da superfície e, ou, segundo Myazawa et al. $(1992,1993)$, da formação de complexos organometálicos nas paredes destes canais, quando há o processo de decomposição das raízes e a liberação de compostos orgânicos por microrganismos. Resultados semelhantes foram obtidos por Hargrove et al. (1982)

Nos tratamentos em que foram utilizadas doses menores de calcário (50S e 25S), foi observada a maior presença de raízes até os 0,075 m (Figuras 5, 6, e 7), profundidade em que houve uma neutralização parcial do $\mathrm{Al}^{3+}$ (Figura 2). Tal comportamento também pode estar relacionado com a menor quantidade de calcário 


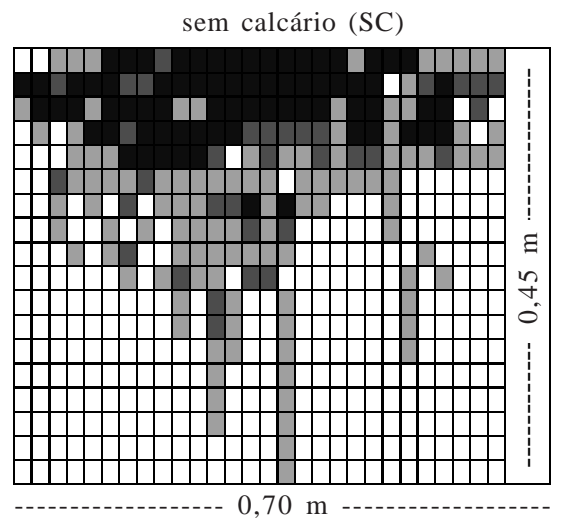

$25 \%$ da dose em superfície (25S)

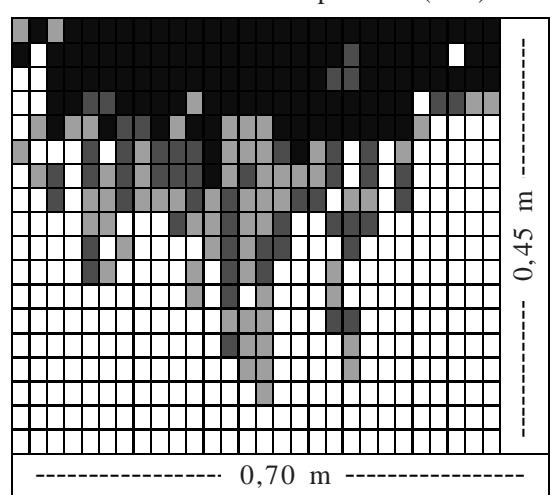

$50 \%$ da dose em superfície (50S)

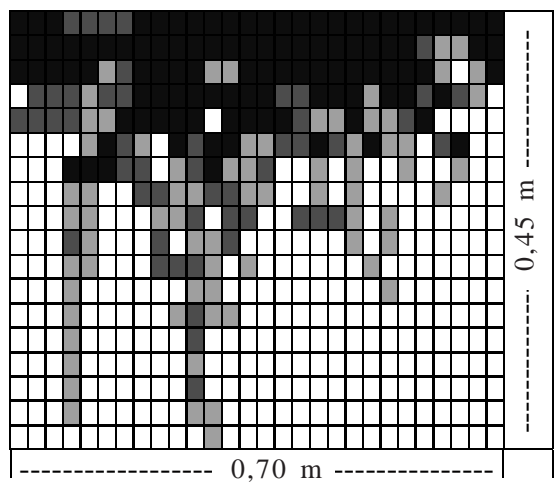

$100 \%$ da dose em superfície (100S)

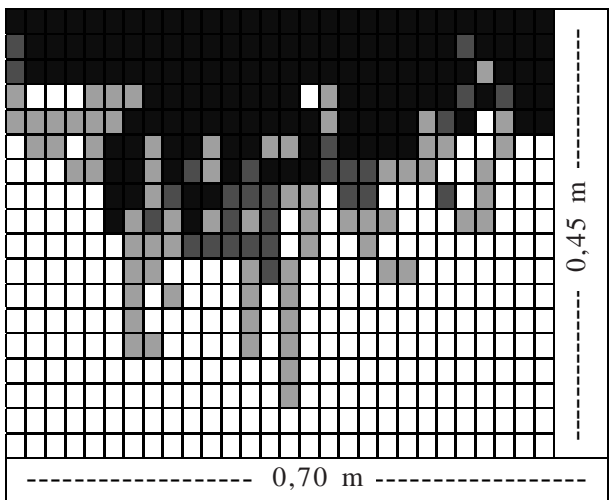

$100 \%$ da dose incorporada (100I)
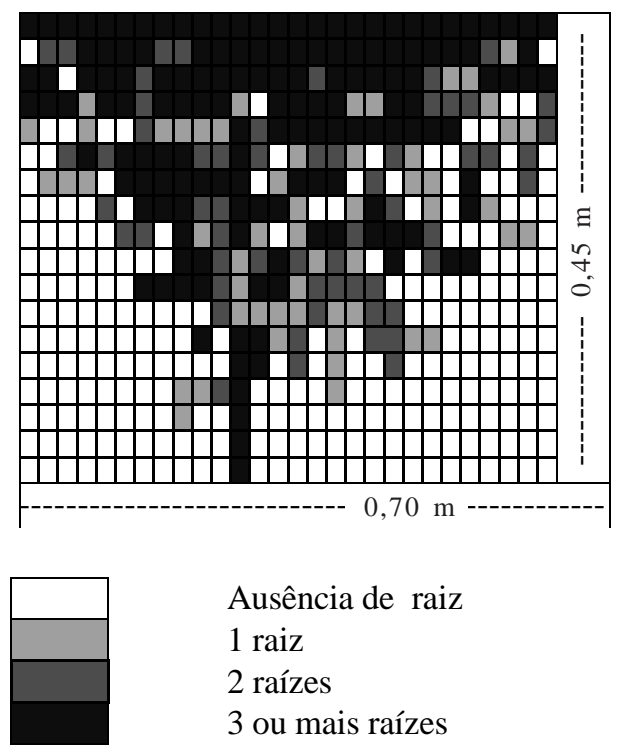

Ausência de raiz

1 raiz

2 raízes

3 ou mais raízes

Figura 7. Perfil de enraizamento da cultura do milho aos 80 dias da emergência no Argissolo Vermelho distrófico arênico sob semeadura direta.

aplicada, desfavorecendo a movimentação física das partículas do corretivo para camadas subsuperficiais e, ou, com a maior disponibilidade de nutrientes e adequado conteúdo de água na camada mais superficial do solo (Eltz et al., 1989; Santos, 1997). Estas características do sistema semeadura direta favorecem a concentração de raízes na camada mais superficial do solo.

Mesmo encontrando no perfil do solo valores de $\mathrm{pH}$

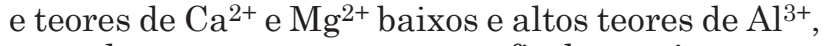
em todos os tratamentos, os perfis de enraizamento apresentaram crescimento de raízes até à profundidade estudada de $0,45 \mathrm{~m}$.

\section{CONCLUSÕES}

1. A incorporação do calcário proporcionou maior uniformidade na neutralização da acidez do solo em profundidade, o que se refletiu em maior quantidade de raízes até $0,45 \mathrm{~m}$, do que os tratamentos com aplicação superficial, que tiveram maior concentração de raízes na camada até $0,075 \mathrm{~m}$.

2. O aumento das doses de calcário aplicado em superfície (25S, 50S e 100S) proporcionou aumento na profundidade em que foram observadas elevações dos valores de $\mathrm{pH}$ e teores de $\mathrm{Ca}^{2+}{\mathrm{e} \mathrm{Mg}^{2+}}^{2}$ e redução do $\mathrm{Al}^{3+}$. 
3. Mesmo em ambiente químico adverso, em todos os tratamentos, os perfis mostraram presença de raízes de milho até $0,45 \mathrm{~m}$ de profundidade.

\section{LITERATURA CITADA}

AMADO, T.J.C. \& .REINERT, D.J. No tillage as a tool for sustainable agriculture in South Brazil. In: BENITES, J.; CHUMA, E.; FOWLER, R.; KENZLE, J.; MANU, R.; NYAGUMBO, I.; STEINER, K. \& VEENHUIZEN, R. van, Orgs. CONSERVATION TILLAGE FOR SUSTAINABLE AGRICULTURE. Harare, Zimbabwe, 1998. p.227-237.

BRASIL. Ministério da Agricultura. Serviço Nacional de Pesquisa Agropecuária. Divisão de Pesquisa Pedológica. Levantamento dos Solos do Estado do Rio Grande do Sul. Recife, 1973. 431p. (Boletim Técnico, 30)

CAIRES, E.F. \& FONSECA, A.F. Absorção de nutrientes pela soja cultivada no sistema de semeadura direta em função da calagem na superfície, Bragantia, 59:213-220, 2000.

CASSOL, L.C. \& ANGHINONI, I. Alterações nas características de um solo Podzólico Vermelho-Amarelo após quatro anos de cultivo nos sistemas semeadura direta e convencional. In: CONGRESSO BRASILEIRO DE CIÊNCIA DO SOLO, 25., 1993, Viçosa. Resumos. Viçosa, MG, Sociedade Brasileira de Ciência do Solo ,1995. p.1843-1844.

CERVI, E.U. Semeadura direta News. A Granja, 628:.55-57, 2001.

COMISSÃO DE FERTILIDADE DO SOLO RS/SC.CFSRS/SC. Recomendações de adubação e de calagem para os Estados do Rio Grande do Sul e de Santa Catarina. 3.ed. Passo Fundo, Sociedade Brasileira de Ciência do Solo, 1994. 224 p.

DAROS, E.; ZAMBON, J.L.C.; WEBER, H.; IDO, O.T.; GRACIANO, P.A. \& ZANETTE, F. Desenvolvimento e distribuição de raízes de diferentes culturas em condições de rizotron, no Paraná. In: WORKSHOP SOBRE SISTEMA RADICULAR: METODOLOGIAS E ESTUDOS DE CASOS, 1999, Aracaju. Anais. Aracaju, Embrapa/ Tabuleiros Costeiros, 1999. p. 167-177.

ELTZ, F.L.F.; PEIXOTO, R.T.G. \& JASTER, F. Efeito de sistemas de preparo de solo nas características físicas e químicas de um Latossolo Bruno álico. R. Bras. Ci. Solo, 13:259-267, 1989.

EMPRESA BRASILEIRA DE PESQUISA AGROPECUARIA EMBRAPA. Centro Nacional de Pesquisa de Solos. Sistema Brasileiro de Classificação de Solos. - Brasilia, Embrapa produção de Informação; Rio de Janeiro, Embrapa Solos, 1999. 412 p.

FAQUIM, V. \& VALE, F.R. Toxidez de alumínio e de manganês. Inf. Agropec.15:28-37, 1991.
FRANCHINI, J.C.; MALAVOLTA, E.; MIYAZAWA, M. \& PAVAN, M.A. Alterações químicas em solos ácidos após aplicação de resíduos vegetais. R. Bras. Ci. Solo, 23:533$542,1999$.

HARGROVE, W.L.; REID, J.T.; TOUCHTON, J.T. \& GALLAHER, R.N. Influence of tillage practices on the fertilitty status of an acid soil double-cropped to wheat and soybeans. Agron. J., 74:684-687, 1982.

LAL, R. \& VAN DOREN Jr., D.M. Influence of 25 years of continuous corn production by three tillage methods on water infiltration for two soils in Ohio. Soil Till. Res., 16:71-84, 1990.

MIELNICZUK, J.; BURLE, M.; FERNANDES, S.V.; BAYER, C. \& AMADO, T.J.C. Eficiência da aplicação de calcário em sistemas de culturas e preparos do solo. In: CONGRESSO BRASILEIRO DE CIÊNCIA DO SOLO, 25., 1995, Viçosa, MG. Resumos. Viçosa,MG, Sociedade Brasileira de Ciência do Solo, 1995. p. 1848-1850.

MYAZAWA, M.; CHIERICE, G.O. \& PAVAN, M.A. Amenização da toxidade de alumínio às raízes das plantas do trigo pela complexação com acidos orgânicos. R. Bras. Ci. Solo, 16: 209-215, 1992

MYAZAWA, M.; PAVAN, M.A. \& CALEGARI, A. Efeito de material vegetal na acidez do solo. R. Bras. Ci. Solo, 17: 411-416, 1993

PEDÓ, F. Rendimento e distribuição de raízes de seis espécies de plantas em dois níveis de compactação de solo. Porto Alegre, Universidade Federal do Rio Grande do Sul, 1986.92p. (Tese de Mestrado)

PÖTTKER, D.; AMBROSI, I.; DENARDIN, J.E.; BEN, J.R. \& KOCHHANN, R.A. Calagem em plantio direto, Passo Fundo, 1998. 37p. (EMBRAPA CNPTRIGO, Boletim Técnico, 4)

SALET, R. L. Dinâmica de íons na solução de um solo submetido a diferentes sistemas de manejo. Porto Alegre, Universidade Federal do Rio Grande do Sul, 1994.110p. (Tese de Mestrado)

SANTOS, E.J.S. Aplicação de calcário em solos arenosos sob sistema semeadura direta e campo nativo.Santa Maria, Universidade Federal de Santa Maria, 1997.66p. (Tese de Mestrado)

TEDESCO, M.J.; VOLKWEIS, S.J. \& BOHNEN, H. Análise de solo, plantas e outros materiais. Porto Alegre, Universidade Federal do Rio Grande do Sul, 1995. 188p. (Boletim, 5)

VIDOR, C.O. Manejo do solo e a população de organismos. In: SIMPÓSIO DE MANEJO DO SOLO E SEMEADURA DIRETA NO SUL DO BRASIL, 1984, Passo Fundo. Anais. Passo Fundo, PIUCS/UPF, 1984. p.36-63. 